\title{
Conduct Disorder: A Review of the Literature and the Impact on Caregivers
}

\author{
Ryan Doucet ${ }^{1}$, BSc; Rima Azar'1,2, PhD; Shelley Doucet, 4, PhD, RN; and Alison \\ Luke $^{3,4}, \mathrm{PhD}$ \\ 1 Psychobiology of Stress \& Health Lab, Mount Allison University \\ 2 Department of Psychology, Mount Allison University \\ ${ }^{3}$ Department of Nursing \& Health Sciences, University of New Brunswick \\ ${ }_{4}^{4}$ Dalhousie Medicine New Brunswick
}

DOI: https://doi.org/10.15273/hpj.v1i2.10661

\begin{abstract}
Introduction: Conduct disorder (CD) is a problematic psychiatric disorder that presents significant challenges for caregivers and families. CD itself has an abundance of literature, although minimal focus has been given toward caregiver mental health and overall well-being. Objectives: This paper reviewed the literature on the burden of caring for youth with $\mathrm{CD}$ on caregivers' mental health. Specifically, we (a) briefly synthesized the existing knowledge on the impact of CD on caregivers while pointing to gaps in literature, and (b) provided recommendations to clinicians caring for youth with CD and their families. Methods: Using specific inclusion/exclusion criteria, we located published studies from 2000-2020 on CD and caregivers' mental health from PsycInfo and PubMed. Results: The four articles that met inclusion criteria for this review utilized different scales and interview techniques to measure caregiver strain, making quantitative comparisons challenging. However, three prevalent reoccurring themes were present among these articles: an increase in caregiver negative emotional states, poor parent-child relationships, and adverse effects on caregivers' spousal relations while caring for a youth with CD. Conclusion/Discussion: This literature review noted the paucity of empirical research on $\mathrm{CD}$ and caregiver strain. Our findings reiterate the negative impact this disorder has on caregivers' mental health, child-parent relationships, and spousal relations. $\mathrm{CD}$ is responsible for substantial societal costs due to criminality and special education arrangements; however, many secondary issues of CD may be offset through access to parenting programs such as Triple $\mathrm{P}$ and proper access to clinical support teams.
\end{abstract}




\section{Conduct Disorder: A Review of the Literature and the Impact on Caregivers}

Conduct disorder (CD), primarily characterized by aggression toward people and animals, property destruction, theft, and serious rule violations, is a problematic psychiatric disorder that generates significant impairment of daily functioning (American Psychiatric Association, 2013). The worldwide prevalence of CD in children and adolescents is an estimated $2.1 \%$ according to data pooled from 41 studies (Polanczyk et al., 2015). Nearly two-thirds of parents of youth with CD report feeling depressed, while a notable group of $30.9 \%$ report seeing a doctor due to difficulty coping with their child's disorder (Meltzer et al., 2011). Most of the early and recent research on $\mathrm{CD}$ has focused almost exclusively on the diagnosed youth, omitting caregivers (ManorBinyamini, 2012). Specifically, epidemiological studies are limited, and the majority of these are not focused on caregivers (Meltzer et al., 2011). This review of the literature addressed this gap by focusing on caregivers, which we defined as an unpaid individual who cares for a youth with CD. Extrapolating from findings on other psychiatric conditions, such as mothers caring for an adolescent with depression (Armitage et al., 2020), studying caregivers' strain is crucial to improve not only their lives but those of the entire family.

Over the past decades, research has shown that multiple factors may contribute to the behavioural symptoms of CD (Pardini \& Frick, 2013). If researchers develop a more rigorous etiological understanding of $\mathrm{CD}$, it may aid in refining future treatments and interventions (Salvatore \& Dick, 2018). A literature review by Salvatore and Dick (2018) compiled results from five studies with an estimated 32,815 twins from the USA, Sweden, and Australia. Their review found a modest to moderate influence of a genetic contribution for CD. A genetic contribution, of course, generates a higher disposition for $\mathrm{CD}$, although it does not guarantee an outcome (Salvatore \& Dick, 2018). The authors point out that even though individuals may have high predispositions to the disorder, some may never develop CD. As highlighted in Salvatore and Dick's (2018) review, it was found that both parent-child conflict (Burt \& Klump, 2014) and parental struggle with drug dependency (Haber et al., 2010) contributed to the presence of CD phenotypes. The impact on caregivers raising a child or youth with $C D$ can be significantly detrimental to both their physical and psychological well-being (Meltzer et al., 2011). Caregivers and families must navigate potential psychosocial harms, such as conflict, spousal problems and feelings of helplessness, all the while attempting to care for their child/youth with CD and other children (Sajadi et al., 2020).

\section{Objectives}

Building on the above findings and gaps in the published studies, our paper examined the current literature on CD and caregiver strain; more specifically, we investigated the impact that caring for a youth diagnosed with CD has on a caregiver's overall well-being and health. Our review is necessary to shed light on caregivers' challenges in managing a youth's CD behaviours, in addition to providing an overview of societal costs (e.g., school dropout, licit or illicit drug use, violence, familial conflicts, law breaking, and risk for out-of-home placements, including foster care, residential services, or even the juvenile justice system). It was predicted that caregiver strain, psychological well-being, and familial stress will all be negatively affected while caring for a CD youth.

\section{Methods}

We conducted a literature review on the impact of caring for youth with CD on caregivers' mental health. We performed a title and abstract search on PsycInfo and PubMed using the following keywords: conduct disorder, conduct disorders, conduct disordered, conductdisordered; caregiver, caregivers, care givers, carers, parent, parents, parental, mother, mothers, father, fathers; and burden, stress, fatigue, burnout, strain, impact, effect, effects, affect, affects, challenge, challenges. Inclusion 
criteria consisted of the following: (a) empirical studies analyzing CD's emotional impact on caregivers, (b) articles published between 2000-2020, and (c) articles published in English. Exclusion criteria included the following: (a) studies analyzing caregiver strain reduction after the implementation of a parent training program or a pharmacological treatment, and (b) studies incorporating participants with CD symptomatology without an official diagnosis. Article titles and abstracts were individually reviewed for keywords and related material. Figure 1 illustrates the selection process used throughout this review.
After the first co-author (RD) performed a title and abstract review of all articles, 17 were selected for a full text review by both RD and RA.

Thirteen of these articles were excluded for one of three reasons: (a) not focusing on CD, (b) youth lacking an official diagnosis, or (c) lacking a focus on caregiver strain. In total, four articles were included in this review.

\section{Results}

Each study analyzed caregiver strain using different methods; therefore, comparison is challenging. As shown in Table 1, the included

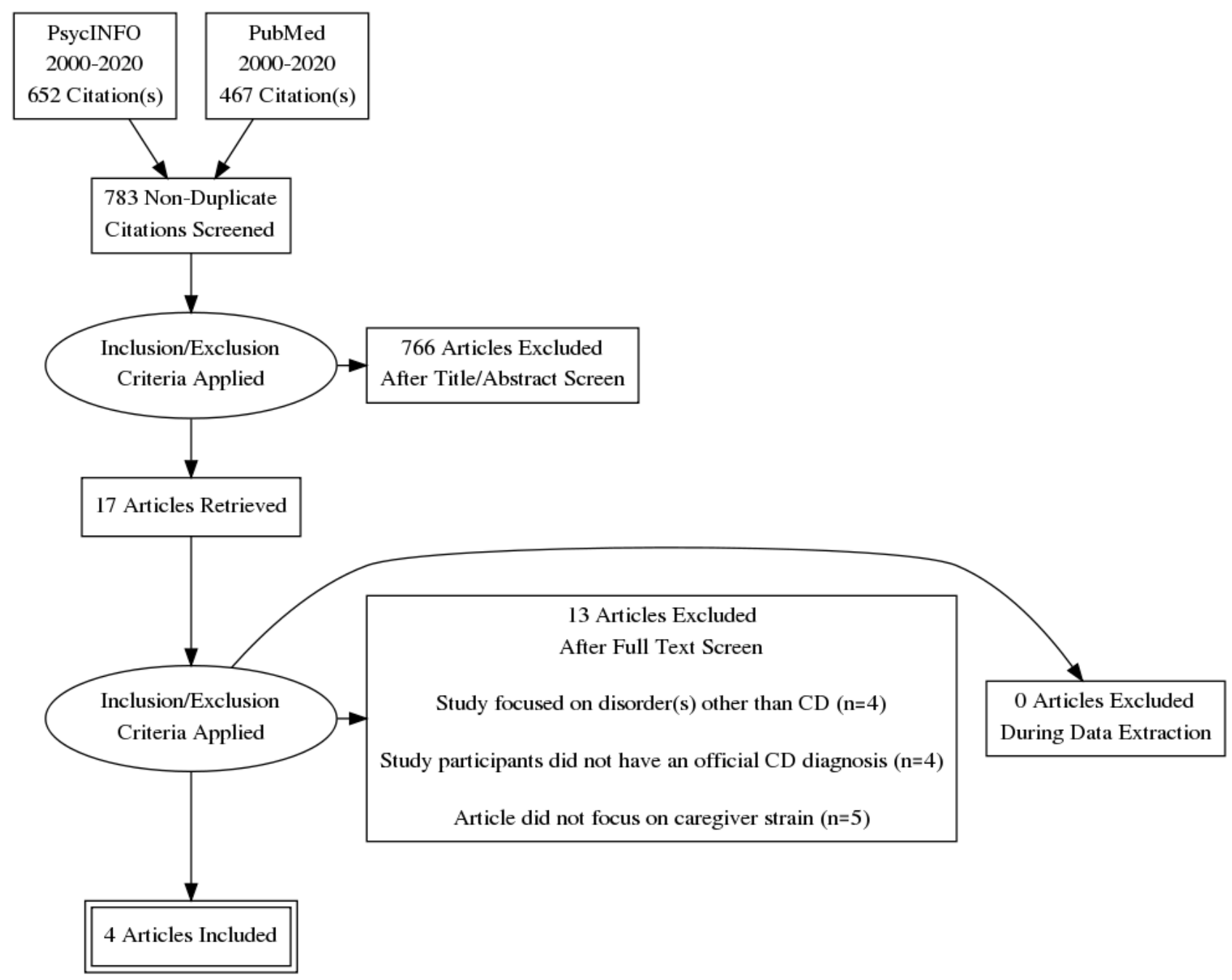

Figure 1

PRISMA Flowchart of Article Selection

HPJ · Fall 2021 · 1(2) | Page 51 


\begin{tabular}{|l|l|l}
\hline $1 D T$ & $\begin{array}{l}\text { HEALTHY } \\
\text { POPULATIONS } \\
\text { JOURNAL }\end{array}$ \\
\hline
\end{tabular}

Table 1

Compiled Studies Analyzing Caregiver Burden of Caring for Youth/Children with Conduct Disorder (CD)

\begin{tabular}{|c|c|c|c|c|c|}
\hline Study & Design & Sample & Assessments & Results & Limitations \\
\hline $\begin{array}{l}\text { Chaudhury } \\
\text { et al. } \\
(2020) \\
\text { India }\end{array}$ & $\begin{array}{l}\text { Cross- } \\
\text { sectional, } \\
\text { hospital } \\
\text { based } \\
\text { comparative } \\
\text { study }\end{array}$ & $\begin{array}{l}120 \text { parents; } \\
60 \text { parents ( } 30 \\
\text { mothers and } \\
30 \text { fathers) of } \\
\text { children (8-16 } \\
\text { years of age) } \\
\text { with CD/ODD, } \\
60 \text { parents of } \\
\text { unaffected } \\
\text { children (8-16 } \\
\text { years of age) }\end{array}$ & $\begin{array}{l}\text { C3-P; GHQ- } \\
\text { 12; KSESS; } \\
\text { PRQ; MQS }\end{array}$ & $\begin{array}{l}\text { Parent-child relationship: } \\
\text { Parents in the CD/ODD group reported lower levels } \\
\text { of attachment, involvement, and parenting } \\
\text { confidence. Parents of the study group also reported } \\
\text { significantly higher levels of relational frustration } \\
\text { Spousal quality: } \\
\text { Parents in the CD/ODD group reported poorer } \\
\text { marital quality. }\end{array}$ & $\begin{array}{l}\text { Diagnoses: } \\
\text { This study } \\
\text { incorporates children } \\
\text { diagnosed with both } \\
\text { CD/ODD }\end{array}$ \\
\hline $\begin{array}{l}\text { Manor- } \\
\text { Binyamini } \\
(2012) \\
\text { Israel }\end{array}$ & $\begin{array}{l}\text { Cross } \\
\text { sectional } \\
\text { comparison } \\
\text { study }\end{array}$ & $\begin{array}{l}400 \text { parental } \\
\text { couples; } 300 \\
\text { parents of } \\
\text { children (6-18 } \\
\text { years of age) } \\
\text { with CD, and } \\
100 \text { parents of } \\
\text { children } \\
\text { without CD) }\end{array}$ & $\begin{array}{l}\text { CSI; SOC } \\
\text { Index }\end{array}$ & $\begin{array}{l}\text { Caregiver burden: } \\
\text { Parents of youth with CD reported significantly } \\
\text { higher levels of caregiver strain } \\
\text { Sense of coherence: } \\
\text { Parents of youth with CD reported significantly } \\
\text { lower sense of coherence levels }\end{array}$ & $\begin{array}{l}\text { Generalizability: } \\
\text { 33\% of youth } \\
\text { diagnosed with CD had } \\
\text { comorbid attention } \\
\text { deficit hyperactivity } \\
\text { disorder }\end{array}$ \\
\hline $\begin{array}{l}\text { Meltzer et } \\
\text { al. (2011) } \\
\text { United } \\
\text { Kingdom }\end{array}$ & $\begin{array}{l}\text { Secondary } \\
\text { analysis of a } \\
\text { (British) } \\
\text { national } \\
\text { survey data } \\
\text { set }\end{array}$ & $\begin{array}{l}10,438 \\
\text { children (5-15 } \\
\text { years of age) a } \\
\text { part of a } \\
\text { nationally } \\
\text { representative } \\
\text { survey }\end{array}$ & $\begin{array}{l}\text { DAWBA; } \\
\text { CABA }\end{array}$ & $\begin{array}{l}\text { Caregiver burden: } \\
\text { Compared to the emotional disorder group, CD } \\
\text { generated higher levels of caregiver burden in many } \\
\text { areas: } \\
\text { - Child with CD generated psychological illness in } \\
\text { parents to some }(18.2 \%) \text { or to a great }(9.9 \%) \\
\text { extent ( } \mathrm{n}=312) \\
\text { Coping difficulties leading to medical } \\
\text { consultation }(30.9 \% ; \mathrm{n}=297) \\
\text { Increased smoking (if participants smoked; } \\
49.3 \% ; \mathrm{n}=224)\end{array}$ & $\begin{array}{l}\text { Sampling bias: } \\
\text { Individuals who did } \\
\text { not participate or } \\
\text { could not be contacted } \\
\text { (around } 25 \% \text { of } \\
\text { sampled households) } \\
\text { may have experienced } \\
\text { more burden } \\
\text { compared to active } \\
\text { participants }\end{array}$ \\
\hline $\begin{array}{l}\text { Sajadi et } \\
\text { al. (2020) } \\
\text { Iran }\end{array}$ & $\begin{array}{l}\text { Qualitative } \\
\text { study } \\
\text { (conducted } \\
\text { from } \\
\text { January } \\
2019- \\
\text { January } \\
2020 \text { ) }\end{array}$ & $\begin{array}{l}23 \\
\text { participants; } \\
\text { children }(8-12 \\
\text { years of age) } \\
\text { with CD }(n=5) \text {, } \\
\text { their parents } \\
(n=6) \text {, teachers } \\
(n=5) \text {, and } \\
\text { social workers } \\
\text { and } \\
\text { psychology } \\
\text { experts }(n=7)\end{array}$ & $\begin{array}{l}\text { Interviews - } \\
\text { Directed } \\
\text { content } \\
\text { analysis }\end{array}$ & $\begin{array}{l}\text { Caregiver burden: } \\
\text { Five themes related to parental strain } \\
\text { emerged from the data: } \\
\text { - Marital problems } \\
\text { - } \quad \text { Feelings of helplessness and an inability to } \\
\text { improve the conditions } \\
\text { - Inappropriate discipline behaviours } \\
\text { - } \quad \text { Parents' lack of interest in obtaining treatment } \\
\text { - for their troubled child } \\
\text { Psychosocial harms of the family members }\end{array}$ & $\begin{array}{l}\text { Generalizability: } \\
\text { Some participants had } \\
\text { comorbid disorders }\end{array}$ \\
\hline
\end{tabular}

studies noted the impact CD has on caregivers' psychological well-being, caregivers' relationships, and caregiver-child relations. In total, three of the studies selected were crosssectional, two of which analyzed caregiver strain while raising a child/youth with $\mathrm{CD}$ in comparison to families of children without the disorder (Chaudhury et al., 2020; ManorBinyamini, 2012). In addition to parents, the final cross-sectional study incorporated the views of children with $\mathrm{CD}$, teachers, and clinicians (Sajadi et al., 2020). One article utilized a national (British) survey data set to determine strain compared to an emotional disorder group (Meltzer et al., 2011). These elements, discussed in length throughout the articles, will be briefly reviewed below. 


\section{Impact on Caregivers' Psychological Well- Being}

A study conducted by Manor-Binyamini (2012) analyzed parents' sense of coherence while caring for a youth with $\mathrm{CD}$. This study incorporated 300 parents of children aged 6 to 18 with CD (selected from special education schools), and 100 parents of children without CD (selected from standard schooling systems) who served as a control group. The sense of coherence, as described by Antonovsky (1996), reviewed the following three mental states that an individual under stress must navigate: (a) comprehensibility (is the individual able to understand the unfolding situation?), (b) manageability (to what extent does the individual feel the situation is manageable; that is, are coping resources available?), and (c) meaningfulness (is the individual able to find meaning in their current situation?). Using Antonovsky's concept of sense of coherence, Manor-Binyamini (2012) investigated caregiver meaningfulness in addition to parental burden. The authors found that caregiver burden was higher for parents of children with CD, who also reported a lower sense of coherence compared to parents of children without CD.

\section{Impact on Caregivers' Relationships}

CD places tension not only on caregivers exclusively but also on their relationships. One nationally representative UK study, which gathered data from 10,438 children throughout England, Wales and Scotland, found that parents of children with CD reported significantly higher levels of strain when compared to parents of children with emotional disorders (Meltzer et al., 2011). For example, 45.6\% ( $\mathrm{n}=312$ ) of participants raising a child with CD stated that their relationships have become "more strained" with their partner, $17.7 \%(n=312)$ noted that their child's CD problems generated issues with their friends, and just over 25\% ( $\mathrm{n}=312)$ of parents stated that this strain contributed to ending a previous relationship (Meltzer et al., $2011)$. Another study conducted in Iran $(n=23)$ included parents $(n=6)$, teachers $(n=5)$, and children aged 8-12 years diagnosed with $\mathrm{CD}(\mathrm{n}=$ 5), along with social workers and psychology experts ( $\mathrm{n}=7$; Sajadi et al., 2020). The authors found through qualitative interviews that caregiver strain negatively impacted the quality of spousal relationships (Sajadi et al., 2020). For instance, parental relationship issues were almost exclusively associated with the behaviour of a child with CD (Sajadi et al., 2020). Marital infidelity and "emotional divorce" (disconnect) were also reported to be prevalent problems in studied couples (Sajadi et al., 2020). These findings were corroborated by another research study (Chaudhury et al., 2020) on spousal problems in parents $(n=60)$ of youth with CD or Oppositional Defiant Disorder (ODD) in comparison with parents $(n=60)$ from a control group. ODD has some similarities to $\mathrm{CD}$; however, the former is generally regarded as a less overt, or milder form of CD (Burke \& Romano-Verthelyi, 2018). Spouses in Chaudhury et al.'s (2020) study reported feelings of rejection by their partners, unmet affectional needs, helplessness, and lower levels of self-disclosure to their partners.

\section{Impact on Parent-Child Relationship}

The parent-child (caregiver) relationship is crucial in a youth's formative years (Popov \& Ilesanmi, 2015). CD/ODD has also been found to challenge this bond in areas of attachment, communication, and parental involvement (Chaudhury et al., 2020). First, parent-child attachment was hindered by the child's behaviour, as family conflicts likely worsened the already strained connection between youth with CD/ODD and their parents; second, communication between children and their parents was mostly conflictual as parents struggled to understand their child's externalizing behaviour; and third, while mothers struggled to empathize with their child with CD/ODD, fathers tended to limit their caregiving involvement (Chaudhury et al., 2020).

\section{Discussion}

Caregivers face immense burden in their relationships throughout all aspects of their lives: from the caregiver's struggle to relate and empathize with their child/youth (Chaudhury et 
al., 2020), to strained spousal relations (Sajadi et al., 2020), the impact of CD can at times be overwhelming for everyone involved in the caring process. These findings align with our initial predictions, which hypothesized that CD would generate an increase in strain and familial stress and decrease overall psychological wellbeing. However, there are numerous forms of interventions and therapeutic solutions while caring for $\mathrm{CD}$ youth that clinicians should consider (e.g., referral parenting programs). The role of clinicians treating CD in youth, especially during early intervention, is to be first and foremost a helping hand, listening to their anguish and assisting with future improvements (Carpenter, 2005). From these initial stepping stones, a shift toward holistic models of whole family care is crucial to assist youth with CD. Three areas of interest (prevalent themes in our review), which may go overlooked during clinical intakes and assessments, are the utility of parenting programs (Sanders et al., 2014), overarching neighbourhood effects (Jennings et al., 2018), and societal financial burden (Friedli \& Parsonage, 2007; Scott et al., 2001). Each of the following three paragraphs will first present the area of interest, expressed as an integrated summary, and conclude with a related clinical recommendation.

\section{Referral Parenting Programs}

Although not always widely accessible, due to geographical restrictions or financial constraints, caregivers may be offered support programs designed to reduce $\mathrm{CD}$ behavioural symptoms in both online and in-person training classes. Programs such as the Triple P-Positive Parenting Program (Sanders et al., 2014) focus on assisting caregivers with disruptive youth in developing skills and action plans aimed at reducing disorderly symptoms. The impact of the Triple $\mathrm{P}$ program has been shown to be substantial, with reductions in both caregiver depression and coercive parenting (Sanders et al., 2008), improvement in caregiver-youth relationships (Sanders et al., 2014), and an overall reduction in disruptive youth behaviours (Skotarczak \& Lee, 2015). From a preliminary search, no research has been located that reviewed the impact Triple $\mathrm{P}$ had on caregiver strain while caring for a youth with CD; however, it is assumed that the success this parenting program has yielded in treating defiant behaviour would likely also be effective in treating CD symptomology. Based on these findings, clinicians may consider recommendations such as the Triple PParenting Program or other family training programs to help reduce strain and provide a support network for affected individuals.

\section{Neighbourhood Effects}

A recent upsurge of published research has now shown the impact "neighbourhood effects" have on one's outcome with CD (Jennings et al., 2018). Specifically, the proximal environment where children grow up, including their neighbourhood, school, and play areas, is vital to their overall well-being (Minh et al., 2017). A recent literature review that incorporated 47 empirical studies from 2001 to 2016, reported a significant link between CD and neighbourhood effects (Jennings et al., 2018). From the clinician standpoint, perhaps the most imperative findings of the aforementioned literature review are not the factors that can increase CD symptoms, but rather, actions that may either prevent CD or improve its prognosis. Jennings et al.'s (2018) literature review indicated six prominent mediating and moderating factors. Mediators in the relationships among neighbourhood effects, $C D$, and $C D$ behaviours included stressful life events (Katz et al., 2012; Roosa et al., 2005), youth conflicts with peers and parents (Roosa et al., 2005), and maternal stress (Linares et al., 2001). Moderators included sex and ethnicity (Oshio, 2008), age (Riina et al., 2014), and parental monitoring (Glickman, 2003). Given these complex data, clinicians may favour ecological (multi-systems) family-based models, as either early preventive measures or interventions to reduce symptom severity.

\section{Financial Burden}

Another theme that emerged from the literature, although beyond the scope of this review, was financial burden. Substantial 
differences in costs are found when comparing youth with $\mathrm{CD}$ to control groups. The largest contributing factors included criminality, educational costs, housing costs, state benefits, and health care (Scott et al., 2001). Another longitudinal American study incorporated participants from four distinct low socioeconomic communities. The researchers followed CD adolescents over a seven-year period. Compared to youth without CD, a substantial expense contrast was present, along with additional public expenditures (over seven years), that reportedly exceeded USD $\$ 70,000$ (CAD \$81,417; Foster et al., 2005). According to Foster et al. (2005) these costs are notably higher than comparable disorders such as ODD. Although the above findings review societal costs, low-income families will likely struggle to afford psychotherapy sessions, pharmacological treatments, and travel to access such services. Clinicians may consider support and navigational interventions to help families access financial assistance programs.

\section{Conclusion}

It is clear that clinicians and support programs alike must work to assist caregivers, all the while understanding the plethora of genetic, psychological, and socio-economic factors that play a role in the etiology of CD. There may be a need for a shift of the focus on youth with $\mathrm{CD}$ toward resilience holistic intervention models for the whole family, community, and systems surrounding youth with $\mathrm{CD}$ or at-risk youth. Understanding the impact of CD on caregivers will allow mental health professionals to not only develop improved treatment plans but also provide a better family quality of life. This review was predominately limited in regard to available literature, as only four articles met our inclusion criteria; future studies may wish to expand keywords to incorporate disruptive behavioural disorders and isolate CD from ODD findings. Additionally, future studies may wish to incorporate articles published prior to the year 2000; although this review was restricted due to first co-author time constraints, older articles may have been overlooked. This literature review summarized the limited available empirical studies of CD's impact on caregivers, which corroborated findings on adolescent depression (Armitage et al., 2020) and attention deficit hyperactivity disorder (ADHD; Evans et al., 2009). Caregiver strain was best predicted in carers of youth with ADHD who presented oppositional and delinquent behavioural patterns (Evans et al., 2009). Overall, this paper noted the immense strain $C D$ places on caregivers, care providers and society at large.

\section{References}

American Psychiatric Association. (2013). Diagnostic and statistical manual of mental disorders (5th ed.). https://doi.org/10.1176/appi.books.97 80890425596

Antonovsky, A. (1996). The salutogenic model as a theory to guide health promotion. Health Promotion International, 11(1), 11-18. https://doi.org/10.1093/heapro/11.1.1 1

Armitage, S., Parkinson, M., Halligan, S., \& Reynolds, S. (2020). Mothers' experiences of having an adolescent child with depression: An interpretative phenomenological analysis. Journal of Child and Family Studies, 29(6), 16171629. https://doi.org/10.1007/s10826020-01705-5

Burke, J. D., \& Romano-Verthelyi, A. M. (2018). Oppositional defiant disorder. In M. M. Martel (Ed.), Developmental pathways to disruptive, impulse-control, and conduct disorders (pp. 21-52). Elsevier. https://doi.org/10.1016/B978-0-12811323-3.00002-X

Burt, S. A., \& Klump, K. L. (2014). Parent-child conflict as an etiological moderator of childhood conduct problems: An example of a 'bioecological' geneenvironment interaction. Psychological Medicine, 44(5), 1065-1076. https://doi.org/10.1017/S0033291713 001190 
Carpenter, B. (2005). Early childhood intervention: Possibilities and prospects for professionals, families and children. British Journal of Special Education, 32(4), 176-183. https://doi.org/10.1111/j.14678578.2005.00394.x

Chaudhury, P., Bhattacharya, B., \& Saha, P. K. (2020). Parent-child relationship and marital quality of parents of conduct or oppositional defiant disorder and unaffected individuals: A comparative study. Psychological Studies, 65(2), 124136. https://doi.org/10.1007/s12646019-00543-w

Evans, S. W., Sibley, M., Serpell, Z. N. (2009). Changes in caregiver strain over time in young adolescents with ADHD: The role of oppositional and delinquent behavior. Journal of Attention Disorders, 12(6), 516-524. https://doi.org/10.1177\%2F10870547 08322987

Foster, E. M., Jones, D. E., \& The Conduct Problems Prevention Research Group. (2005). The high costs of aggression: Public expenditures resulting from conduct disorder. American Journal of Public Health, 95(10), 1767-1772. https://doi.org/10.2105/ajph.2004.061 424

Friedli, L., \& Parsonage, M. (2007, November). Mental health promotion: Building an economic case. Northern Ireland Association for Mental Health. https://www.researchgate.net/publicat ion/308339133_Mental_health_promoti on_building_an_economic_case

Glickman, A. R. (2003). Parental monitoring of children exposed to community violence: Predicting externalizing behaviors (Publication No. 3096375) [Doctoral dissertation, University of Miami]. ProQuest Dissertations Publishing.

Haber, J. R., Bucholz, K. K., Jacob, T., Grant, J. D., Scherrer, J. F., Sartor, C. E., Duncan, A. E., \& Heath, A. (2010). Effect of paternal alcohol and drug dependence on offspring conduct disorder: Gene- environment interplay. Journal of Studies on Alcohol and Drugs, 71(5), 652-663.

https://doi.org/10.15288/jsad.2010.71 .652

Jennings, W. G., Perez, N. M., \& Reingle Gonzalez, J. M. (2018). Conduct disorder and neighborhood effects. Annual Review of Clinical Psychology, 14, 317341. https://doi.org/10.1146/annurevclinpsy-050817-084911

Katz, B. N., Esparza, P., Carter, J. S., Grant, K. E., \& Meyerson, D. A. (2012). Intervening processes in the relationship between neighborhood characteristics and psychological symptoms in urban youth. The Journal of Early Adolescence, 32(5), 650-680.

https://doi.org/10.1177/02724316114 14060

Linares, L. O., Heeren, T., Bronfman, E., Zuckerman, B., Augustyn, M., \& Tronick, E. (2001). A mediational model for the impact of exposure to community violence on early child behavior problems. Child Development, 72(2), 639-652. https://doi.org/10.1111/14678624.00302

Manor-Binyamini, I. (2012). Parenting children with conduct disorder in Israel: Caregiver burden and the sense of coherence. Community Mental Health Journal, 48(6), 781-785.

https://doi.org/10.1007/s10597-0119474-x

Meltzer, H., Ford, T., Goodman, R., \& Vostanis, P. (2011). The burden of caring for children with emotional or conduct disorders. International Journal of Family Medicine, 2011, Article 801203. https://doi.org/10.1155/2011/801203

Minh, A., Muhajarine, N., Janus, M., Brownell, M., \& Guhn, M. (2017). A review of neighborhood effects and early child development: How, where, and for whom, do neighborhoods matter? Health \& Place, 46, 155-174. 
https://doi.org/10.1016/j.healthplace.2 017.04 .012

Oshio, T. (2008). A longitudinal examination of harsh discipline and externalizing behavior: An ecological perspective (Publication No. 3331988) [Doctoral dissertation, Michigan State University]. ProQuest Dissertations Publishing.

Pardini, D., \& Frick, P. J. (2013). Multiple developmental pathways to conduct disorder: Current conceptualizations and clinical implications. Journal of the Canadian Academy of Child and Adolescent Psychiatry, 22(1), 20-25. https://www.cacap-acpea.org/wpcontent/uploads/MultipleDevelopmental-Pathways-Pardini.pdf

Polanczyk, G. V., Salum, G. A., Sugaya, L. S., Caye, A., \& Rohde, L. A. (2015). Annual research review: A meta-analysis of the worldwide prevalence of mental disorders in children and adolescents. Journal of Child Psychology and Psychiatry, 56(3), 345-365. https://doi.org/10.1111/jcpp.12381

Popov, L. M., \& Ilesanmi, R. A. (2015). Parentchild relationship: Peculiarities and outcome. Review of European Studies, 7(5), 253-263. https://doi.org/10.5539/res.v7n5p253

Riina, E. M., Martin, A., \& Brooks-Gunn, J. (2014). Parent-to-child physical aggression, neighborhood cohesion, and development of children's internalizing and externalizing. Journal of Applied Developmental Psychology, 35(6), 468477. https://doi.org/10.1016/j.appdev.2014 .04 .005

Roosa, M. W., Deng, S., Ryu, E., Burrell, G. L., Tein, J.-Y, Jones, S., Lopez, V., \& Crowder, S. (2005). Family and child characteristics linking neighborhood context and child externalizing behavior. Journal of Marriage and Family, 67(2), 515-529. https://doi.org/10.1111/j.00222445.2005.00132.x
Sajadi, S., Raheb, G., Maarefvand, M., \& Alhosseini, K. A. (2020). Family problems associated with conduct disorder perceived by patients, families and professionals. Journal of Education and Health Promotion, 9, Article 184. https://doi.org/10.4103/jehp.jehp_110 _20

Salvatore, J. E., \& Dick, D. M. (2018). Genetic influences on conduct disorder. Neuroscience and Biobehavioral Reviews, 91, 91-101.

https://doi.org/10.1016/j.neubiorev.20 16.06.034

Sanders, M. R., Kirby, J. N., Tellegen, C. L., \& Day, J. J. (2014). The Triple P-Positive Parenting Program: A systematic review and meta-analysis of a multilevel system of parenting support. Clinical Psychology Review, 34(4), 337357.

https://doi.org/10.1016/j.cpr.2014.04. 003

Sanders, M. R., Ralph, A., Sofronoff, K., Gardiner, P., Thompson, R., Dwyer, S., \& Bidwell, K. (2008). Every family: A population approach to reducing behavioral and emotional problems in children making the transition to school. The Journal of Primary Prevention, 29(3), 197-222. https://doi.org/10.1007/s10935-0080139-7

Scott, S., Knapp, M., Henderson, J., \& Maughan, B. (2001). Financial cost of social exclusion: Follow up study of antisocial children into adulthood. BMJ, 323. https://doi.org/10.1136/bmj.323.7306. 191

Skotarczak, L., \& Lee, G. K. (2015). Effects of parent management training programs on disruptive behavior for children with a developmental disability: A metaanalysis. Research in Developmental Disabilities, 38, 272-287. https://doi.org/10.1016/j.ridd.2014.12 .004 